\title{
Pulmonary Adenocarcinoma in Dogs: Surgical Treatment with Real-Time Video-Thermometry
}

\author{
Sarah Tavares de Melo ${ }^{1}$, Eduardo Gonçalves da Silva $\varpi^{2}$, Caroline Castagnara Alves $\mathbb{i}^{2}$, Paula Priscila Correia Costa ${ }_{\mathbb{1}}^{2}$, \\ Stefanie Bressan Waller $\mathbb{C}^{2}$, Paula Gebe Abreu Cabral $\mathbb{C}^{3}{ }^{3}$, Igor Ciríaco Barroso' \& André Lacerda de Abreu Oliveira ${ }_{\mathbb{D}}^{3}$
}

\begin{abstract}
Background: Pulmonary neoplasia is an abnormal proliferation of cells at the lung tissue, and may be classified as primary, secondary or metastatic, and multisystemic. However, primary neoplasia is rare in canids. Additionally, neoplasms may be classified according to their biological behavior as either malignant or benign. Malignant tumors are more prevalent. The diagnosis can be difficult due to nonspecific symptoms, taking into account that some affected patients do not have symptoms at all; thus, the real incidence of the disease might remain undiagnosed on certain occasions. Therefore, we aimed to report an unprecedented successful case of lung lobectomy surgery in dogs with the aid of infrared video thermometry, which showed real-time images during the surgical procedure.

Case: A 10-year-old male dog, crossbreed with Cocker Spaniel, was attended with a history of lethargy, dullness, progressive weight loss, cough, and difficulty breathing. Due to the chronic severity of the clinical signs and the normal physiological clinical examination, complementary exams were requested, such as radiography of the cervical and thoracic regions, cranial and thoracoabdominal computed tomography (TCT). The results of the exams showed the presence of a nodule mass in the right caudal pulmonary lobe which caused a lateral deviation to the left hemithorax of the cardiac silhouette. The patient underwent a surgical procedure with an approach through the thoracic region, at the height of the seventh intercostal space, and a total lobectomy was performed. Throughout the surgical procedure, video thermometry in real-time through the MART station (Metabolic Activity in Real-Time FLIR SC $325^{\circledR}$ ) was used to determine the viability of adjacent tissues through temperature differences measured in degrees Celsius. The surgical fragment containing the direct caudal pulmonary lobe and the mass were sent to the pathology sector for anatomopathological evaluation. An abundant papillary epithelial proliferation was visualized through microscopy, presenting areas of necrosis and inflammatory polymorphonuclear infiltrate. The nodule was diagnosed as lung papillary adenocarcinoma.

Discussion: Adenocarcinomas consist of papillary, acinar, solid, or mixed glandular structures. They may originate from the airways, bronchial glands, or bronchoalveolar region, and often show invasive growth presenting a rudimentary and irregular shape. The clinical signs are non-specific, including exercise intolerance, non-productive cough, chronic respiratory signs such as tachypnoea or dyspnea, reduced appetite, weight loss, lethargy, chest palpation pain, hemothorax, pneumothorax, and pleural effusion. The diagnosis is concluded through imaging diagnostic tests, of which chest radiography is the most important, followed by magnetic resonance and computed tomography. Also, histopathological examination is essential to determine a definitive diagnosis. The treatment of choice for adenocarcinoma nodules is a surgical excision of the tumor mass. However, the type of surgical approach is determined by different factors such as size, location, and involvement of adjacent structures. The ablation of pulmonary masses may be performed either via partial or total lobectomies. Nevertheless, partial lobectomy is more often performed on non-neoplastic masses or to obtain material for biopsy, whilst total lobectomy is recommended for a malignant neoplasm removal. The prognosis is always guarded, having a more favorable outcome in masses of the smaller diameter without the involvement of adjacent structures.
\end{abstract}

Keywords: anatomopathological, imaging tests, lung cancer, surgical technique. 


\section{INTRODUCTION}

Considering the increase in life expectancy of pets, there is an increase in the diagnosis of chronic diseases, including neoplasms [27]. As a result, there is a growing demand for an appropriate diagnosis and treatment for this disease, which starts with changes in the DNA [21,24]. Neoplasms are classified according to their biological behavior in two different categories benign and malignant [10], and this establishment occurs through the evaluation of the proportion of growth, degree of cell differentiation, growth pattern, and potential for metastasis. Among the lung neoplasms, we can mention the primary neoplasms, secondary neoplasms or metastases, and multisystemic neoplasms $[3,12,17]$.

Primary lung neoplasms are rare in dogs $[3,16]$, of which the male dogs with an average age of 11-year-old are the most affected [4]. However, this frequency has been increasing in recent years $[3,11,18,20]$. Lung neoplasms are generally difficult to diagnose, which is the main reason for being considered with low incidence. Additionally, the most effective treatment is early surgical excision, and complementary chemotherapy treatment can be performed $[9,17,27]$.

We aimed to report an unprecedented case of pulmonary lobectomy in a dog with the aid of real-time video-thermometry.

\section{CASE}

A 10-year-old male dog, crossbreed with Cocker Spaniel, weighing $9.7 \mathrm{~kg}$, was referred to Animal Experimentation Unit (UEA, Universidade Estadual do Norte Fluminense, Campos dos Goytacazes, RJ, Brazil) for clinical evaluation due to intense tiredness, coughing and difficulty breathing. The patient was brought in by the client after presenting symptoms of difficult breathing, lethargy, dullness, cough, and progressive weight loss. The patient had the vaccination and deworming protocols updated, and no contact with other animals.

A physical examination was performed, and the animal presented an alert state, normal capillary refill time was observed, normal hydration was evidenced through the skin fold test, and the rectal temperature was $38.7^{\circ} \mathrm{C}$. Considering the presented symptoms, a series of complementary tests were performed to assist the diagnosis and therapeutic protocol. The exams consisted of a radiographic examination of the thoracic and cervical regions, and a cranial and thoracoabdominal computed tomography.
The presence of a compromised radiopaque mass throughout the right caudal lobe was identified through radiographic examination of the thoracic region causing a left lateral deviation of the cardiac silhouette. Different areas of the lung presented a compacted bronchial wall and the interstice more evident in the right pulmonary lobes. Also, there was a decrease in expansion and a slight increase in the radiopacity of the pleural space in the retrosternal region. Through radiographic images, it was not possible to visualize enlargement of the cardiac chambers or the diameter of the cardiac and pulmonary vessels. On the radiography of the cervical region, an increase in the right mandibular lymph node was noted; the other structures were preserved anatomically.

Computed tomography (CT) of the thoracoabdominal region showed the presence of a heterogeneous mass and oval shape, located in the right caudal pulmonary lobe, with dimensions of $63.3 \mathrm{~mm}$ on the lateral view, $126.6 \mathrm{~mm}$ on the craniocaudal axis, and $43.5 \mathrm{~mm}$ on the dorsoventral axis. Furthermore, this mass is closely related to the cardiac silhouette, thus promoting compression of the right atrium and moderate displacement of the heart to the hemithorax left. The CT scan of the cranial region showed cerebral parenchyma of morphology and physiological attenuation. Subsequently, the animal was referred to the surgical department to perform the thoracotomy and pulmonary lobectomy procedure.

After pre-anesthetic evaluation, the patient was fit for the procedure and was sedated with chlorpromazine [Longactil ${ }^{\circledR 1}-1.1 \mathrm{mg} / \mathrm{kg}$ ] and morphine [Dimorf ${ }^{\circledR 1}$ - 0.5-2.0 $\mathrm{mg} / \mathrm{kg}$ ] intramuscularly. After sedation, the animal's hair was clipped in the thoracic region. Anesthetic induction was performed through the association of $2.5 \%$ diluted thiopental [Thiopentax ${ }^{\circledR 1}-7.5 \mathrm{mg} / \mathrm{kg}$ ] and propofol [Propovan ${ }^{\circledR 1}-2.5 \mathrm{mg} / \mathrm{kg}$ ] intravenously. This protocol aimed to avoid excessive hypotension caused by Propofol and to seek a circulatory balance. Anesthetic maintenance was performed through the use of isoflurane via inhalation.

The patient was positioned on the surgical table on the left lateral decubitus position, and asepsis was performed with $0.1 \%$ povidone-iodine and $70 \%$ isopropanol in the incision area. A conventional thoracotomy was performed $2 \mathrm{~cm}$ below the angle of the scapula, the skin, and the subcutaneous tissue, sectioning the latissimus dorsal and cranial serratus muscles. The in- 
cision region occurred on the seventh intercostal space; the intercostal muscle was sectioned with the aid of a sterilized stainless steel scalpel on the upper edge of the eighth rib. The paravertebral sacro spinal muscle was removed, and a Finochietto-type rib retractor was positioned to favor thoracic exploration.

The ligament between the middle and caudal lobe was separated, and a double ligature was performed in the caudal pulmonary vein for its isolation and suture with silk thread 0 . The right caudal lobe where the mass was located, was separated cranially, and the caudal pulmonary ligament was sectioned. The right upper pulmonary artery was ligated twice and sutured with 3-0 silk. The bronchi of the basal and upper segments were sectioned and closed using simple single stitches with the same thread. The right caudal lobe containing the mass was excised (Figure 1), and during the surgical procedure, a drain was placed in the pleural cavity to facilitate the outflow of air out of the pleural space and the expansion of the lung. The ribs were re-joined and the muscular layer was closed using nylon 0 thread in the simple continuous pattern. The pulmonary fragment containing the mass was sent for histopathology, packed in $10 \%$ formalin.

During the surgical procedure, a camera from the operator of the Metabolic Activity in Real-Time (MART) station was attached at a distance of approximately $1.5 \mathrm{~m}$ from the surgical procedure, processing images on the monitor in real-time (Figure 2). The MART station allowed the visualization of invisible parts of the electromagnetic spectrum through infrared video thermometry images in three or four dimensions, indicating whether there was a pathological change during the surgery, therefore guiding the surgeon's actions.

Video thermometry images displayed temperature differences of less than 0.1 degrees Celsius between different points of the surgical field through the prototype device, and in this way, all the metabolic activity of the animal was monitored during the surgery. The surgical procedure lasted approximately 30 min and there were no relevant metabolic changes that could compromise the animal's risk during surgery.

Postoperative medications included cephalexin antibiotic [Rilexine ${ }^{\circledR 2}-300 \mathrm{mg}$, every $12 \mathrm{~h}$, for 30 days], analgesic tramadol hydrochloride [Cronidor ${ }^{\circledR 3}$ - $40 \mathrm{mg}$, every $12 \mathrm{~h}$, for 5 days] and anti-inflammatory meloxicam [Meloxytrat ${ }^{\circledR 4}-1 \mathrm{mg} / \mathrm{kg}$, every $24 \mathrm{~h}$, for 3 days]. The animal returned for post-surgical evaluation and removal of the stitches after 13 days. The patient presented stable.

For histopathological examination, three fragments of the mass were sent to the pathology department. Macroscopically, the fragments were characterized as having a whitish color and irregular surface. Microscopically, and abundant epithelial papillary proliferation was found, with signs of anisocytosis, basal vacuolization, areas of necrosis, and moderate polymorphonuclear inflammatory infiltrate. Therefore, through histopathological evaluation, the diagnosis of pulmonary papillary adenocarcinoma was defined.

\section{DISCUSSION}

Primary lung neoplasms are generally malignant $[1,22]$, and most commonly affect elderly animals $[1,4,11,17]$. There is no apparent predilection for breed or sex [23], although the male seems to be more affected [4], similar to our reported case. The origin of this neoplasm can be through any cell from the pulmonary tissue, as epithelial and mesenchymal cells [15,26], being the first type most common [3].

Lungs are a pair of organs with a large vascular supply, in which the neoplastic emboli often migrate through the bloodstream, contributing to the increased incidence of secondary neoplasms in the lungs $[3,25]$. Multisystemic neoplasms are rare in the lungs and may be classified as lymphomas, malignant histiocytosis, or lymphomatoid granulomatosis [3,17].

The classification of lung neoplasms established by the World Health Organization identifies the different types of neoplasms with adaptations [4] as benign (ex. papilloma, papillary adenoma, and bronchioloalveolar adenoma) or malignant (ex. bronchial gland carcinoma, squamous cell carcinoma, adenocarcinoma) epithelial neoplasm; mesenchymal (ex. osteosarcoma and chondrosarcoma); and other tumors (ex. granular cell tumor, lymphomatoid granulomatosis, and malignant histiocytosis).

Moulton et al. [19] established a classification based on the most frequent neoplasms, primary lung carcinomas: adenocarcinoma (differentiated and undifferentiated), squamous cell carcinoma, bronchial cell carcinoma, and alveolar carcinoma (small cell anaplastic and large cell anaplastic). This classification was used by different authors later and the subdivision of adenocarcinomas into bronchogenic, bronchial, and bronchoalveolar glands was added to it $[3,27]$. 


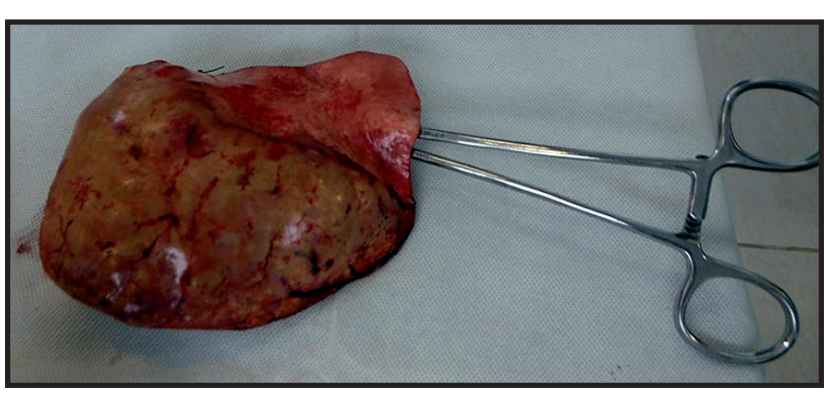

Figure 1. Surgical fragment containing a right caudal pulmonary lobe and tumor mass.

Adenocarcinoma in the lungs is characterized by the invasion and destruction of the lung parenchyma [4] and encompasses a variety of histogenesis [26]. This type of neoplasia was formerly called bronchoalveolar carcinoma when located in the pulmonary lobes [13] as in the case described, where the neoplastic mass involved almost the entire right caudal pulmonary lobe. This classification includes masses composed of papillary, acinar, solid, or mixed glandular structures, in a rudimentary and irregular shape. They may originate from the airways, bronchial glands, or bronchoalveolar region, and often present invasive and destructive growth [14]. They may present satellite nodules originating through lymphatic dissemination, and by air. Distant metastases are extremely rare [3].

Paraneoplastic syndromes occur concomitantly with neoplasms and affect different functions of the organism. They originate from the secretion of substances such as peptides or hormones produced by the tumors, or from an inappropriate immune cross-reaction between normal host cells and initially targeted tumor cells. The most common paraneoplastic syndromes in lung neoplasia are hypertrophic osteopathy, hypercalcemia, generalized neuromyopathy, and hyperadrenocorticism. The causes of hyperadrenocorticism paraneoplastic syndrome include ectopic effusion of adrenocorticotropic hormone (ACTH), stroke fever, and leucocytosis with neutrophilia or eosinophilia $[3,5,10]$. The symptoms occur in most cases, however, about 25 to $30 \%$ of the instances may be asymptomatic, with the diagnosis being made accidentally on chest radiographs $[3,17]$. The symptoms are related to the size of the tumor, and in tumors smaller than 2 to 3 $\mathrm{cm}$, the absence of clinical signs is common. A chronic dry cough is the most frequent of the symptoms, and dyspnoea, tachypnoea, wheezing, and hemoptysis are also commonly found [3,6,27].

Several complementary exams may be used as tools for the diagnosis of lung neoplasms, of which a

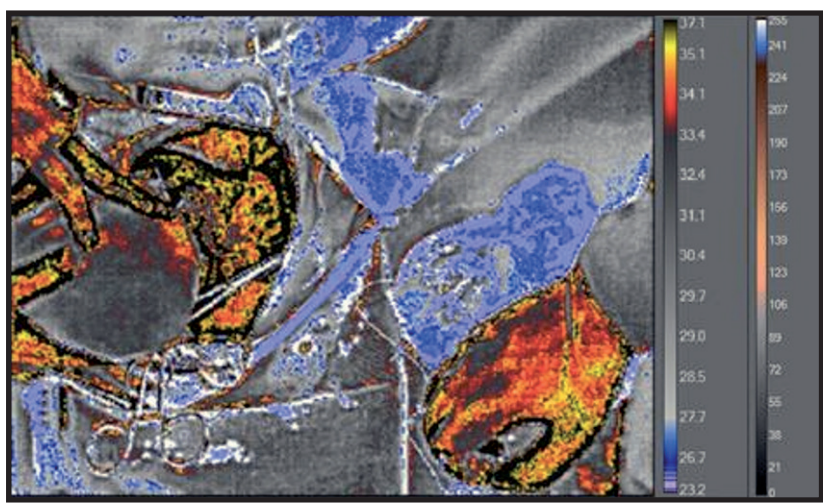

Figure 2. Screen capture of the MART station used during the surgical procedure to show temperature variations on each surface.

thoracic radiograph is the most frequently performed and has the best efficacy for early stages $[3,26]$. Other diagnostic methods include a chest ultrasound, computed tomography, aspiration puncture with an aid of a fine needle, biopsy (transcutaneous, bronchoscopic biopsy through thoracotomy or thoracoscopy), tracheal bronchial lavage, bronchoalveolar lavage, and bronchoscopy $[3,8,26]$. In the reported case, the results of radiographic and computed tomography exams were used to provide greater precision as to the location, size, and involvement of adjacent structures by the neoplastic mass.

Obtaining the definitive diagnosis is carried out through cytology or anatomopathological analysis of material from biopsy or necropsy [2,8]. It is important to collect material to perform this examination to define the tumor type, and thus determine whether a surgical excision is curative or whether there is a need for complementary therapies such as chemotherapy.

To perform the surgery, some criteria must be observed: the tumor must consist of solid masses, metastasis cannot be present, the mass must be intrathoracic, there should not be associated complications, and the animal must be able to undergo the procedure $[3,6,9,27]$. The usual surgical techniques employed are partial lobectomy, total lobectomy, and pneumonectomy; and their choice is linked to the degree of mass extension and the involvement of the lungs [3].

A partial lobectomy is used to collect material for biopsies to determine the tumor type and for the removal of non-neoplastic masses. To perform this technique, mechanical sutures can be used as a stapler [17]. The technique of total lobectomy is used for neoplastic mass removal, where there is greater involvement of the lung lobe parenchyma. When there is a need for a safer approach, it is necessary to isolate and ligature 
the artery, the vein, and the bronchus that make up the target peduncle to perform the procedure [7].

Pneumonectomy can be performed when more than one pulmonary lobe is involved, which is the complete removal of one of the lungs and is a much more aggressive surgery compared to other techniques. In theory, up to $50 \%$ of the lung parenchyma can be removed without affecting or compromising the patient's life, thus the left lung could be removed if necessary due to a major impairment of its structures. However, the right lung could not suffer a complete extirpation as it represents more than half of all lung parenchyma. For this reason, it is impossible to perform this technique on this site [7,9].

The prognosis of pulmonary neoplasia is always guarded. The best outcome for cases of pulmonary neoplasia has been described in patients with masses less than $5 \mathrm{~cm}$ in diameter. These masses were not involved with the regional ganglia and had no association with pleural fluid. Location in the peripheral region of the respective pulmonary lobe also contributes to more successful outcomes [17].
This study reported a surgical technique of pulmonary lobectomy in a canine patient assisted by real-time videothermometry, in which the neoplastic mass was completely removed, and the patient recovered well after the procedure. The surgical treatment with real-time videothermometry showed satisfactory results in the canine case with pulmonary adenocarcinoma, providing a new technical approach.

\section{MANUFACTURERS \\ ${ }^{1}$ Cristália Produtos Químicos Farmacêuticos Ltda. Itapira, SP, Brazil. \\ ${ }^{2}$ Virbac do Brasil Indústria e Comércio Ltda. São Paulo, SP, Brazil. ${ }^{3}$ União Química Farmacêutica Nacional S.A. Embu-Guaçu, SP, Brazil. \\ ${ }^{4}$ Uzinas Chimicas Brasileiras S.A. Jaboticabal, SP, Brazil.}

Acknowledgements. To CAPES (Coordenação de Aperfeiçoamento de Pessoal de Nível Superior) and to CNPq (Conselho Nacional de Desenvolvimento Científico e Tecnológico) for the fellows scholarships.

Declaration of interest. The authors report no conflicts of interest. The authors alone are responsible for the content and writing of the paper.

\section{REFERENCES}

1 Baez J.L. \& Sorenmo K.U. 2004. Pulmonary and bronchial neoplasia. In: King L.G. (Ed). Textbook of Respiratory Disease in Dogs and Cats. St. Louis: Saunders Elsevier, pp.508-516.

2 Bertazzolo W., Zuliani D., Pogliani E., Caniatti M. \& Bussadori C. 2002. Diffuse bronchiolo-alveolar carcinoma in a dog. Journal of Small Animal Practice. 43(5): 265-268. DOI: 10.1111/j.1748-5827.2002.tb00071.x

3 Caldeira S.M.G. 2012. Neoplasias Pulmonares Primárias em Canídeos: Revisão Bibliográfica a Propósito de Quatro Casos Clínicos. 92f. Lisboa, Portugal. Dissertação (Mestrado Integrado em Medicina Veterinária) - Universidade Técnica de Lisboa.

4 Caprioli R.A.,Argenta F.F., Hammerschmitt M.E., Pereira P.R., Lorenzo C., Pavarini S.P., Driemeier D. \& Sonne L. 2018. Pathological and immunohistochemical findings of primary pulmonary neoplams in dogs in the metropolitan region of Porto Alegre, Rio Grande do Sul. Pesquisa Veterinária Brasileira. 38(6): 1151-1158. DOI: 10.1590/16785150-pvb-5206

5 Carothers M.A. \& Alvarez F.J. 2006. Respiratory neoplasia. In: Birchard S.J. \& Sherding R.G. (Eds). Saunders Manual of Small Animal Practice. 3rd edn. St.Louis: Saunders, Elsevier, pp.1708-1714

6 Dhumeaux M.P. \& Haudiquet P.R. 2009. Primary pulmonary osteosarcoma treated by thoracoscopy-assisted lung resection in a dog. The Canadian Veterinary Journal. 50(7): 755-758.

7 Dunning D. 2014. Lung and Thoracic Cavity. In: Bojrab M., Ellison G. \& Slocum B. (Eds). Current Techniques in Small Animal Surgery. 5th edn. Jackson: Teton NewMedia, pp.411-432.

8 Ferian P.E. Silva E.F., Guedes R.C., Tôrres R.C.S. \& Carneiro R.A.2006. Diagnóstico citológico de neoplasia pulmonar por meio de lavado broncoalveolar em uma cadela: Relato de caso. Arquivo Brasileiro de Medicina Veterinária e Zootecnia. 58(5): 776-780. DOI: 10.1590/S0102-09352006000500012

9 Fossum T.W. 2007. Surgery of the lower respiratory system: Lungs and thoracic wall. In: Small Animal Surgery. 3rd edn. St. Louis: Mosby Elsevier, pp.867-895.

10 Fox L.E. \& King R.R. 2002. Cancers of the respiratory system. In: Morrison W.B. (Ed). Cancer in Dogs and Cats: Medical and Surgical Management. 2nd edn. Cheyenne: Teton NewMedia, pp.497-412. 
11 Fox L.E. \& Rissetto K.C. 2010. Primary respiratory tumors. In: Henry C.J. \& Higginbotham M.L. (Eds). Cancer Management in Small Animal Practice. St. Louis: Saunders Elsevier, pp.231-234.

12 Hawkins E.C. 2003. Respiratory system disorders. In: Nelson R.W. \& Couto C.G. (Eds). Small Animal Internal Medicine. 3rd edn. St. Louis: Mosby, pp.210-342.

13 Hochhengger B., Perin F.A., Camargo S.M., Marchiori E., Irion K., Guimarães M.D., Felicetti J.C. \& Camargo J. 2014. Ground-glass nodules and CT-guided placement of platinum coils. Jornal Brasileiro de Pneumologia. 40(4): 450-452. DOI: $10.1590 / \mathrm{S} 1806-37132014000400015$

14 Li C. \& Lu H. 2018. Adenosquamous carcinoma of the lung. OncoTargets and Therapy. 11: 4829-4835.

15 López A. 2007. Respiratory system. In: McGavin M.D. \& Zachary J.F. (Eds). Pathologic Basis of Veterinary Disease. 4th edn. St. Louis: Mosby, pp.463-558.

16 Lucena R.B., Maia L.A., Dantas A.F.M., Nobre V.M.T., Macêdo J.T.S.A., Galiza Filho E.M. \& Barros C.S.L. 2011. Carcinoma bronquíolo-alveolar difuso em um cão: Aspectos clínico-patológicos e imuno-histoquímicos. Ciência Rural. 41(1): 160-163. DOI: 10.1590/S0103-84782011000100026

17 Luís J.P.S., Pontes J.V. \& Carvalho A.P. 2005. Neoplasias primárias do pulmão em canídeos a propósito de três casos submetidos a cirurgia. Revista Portuguesa de Ciências Veterinárias. 100(553-554): 95-102.

18 Marolf A.J., Gibbons D.S., Podell B.K. \& Park R.D. 2011. Computed tomographic appearance of primary lung tumors in dogs. Veterinary Radiology and Ultrasound. 52(2): 168-172. DOI: 10.1111/j.1740-8261.2010.01759.x

19 Moulton J.E., Von Tscharner C. \& Schneider R. 1981. Classification of lung carcinomas in the dog and cat. Veterinary Pathology. 18(4): 513-528. DOI: 10.1177/030098588101800409

20 Oliveira M.C., Costa S.Z.R., Pires A.P.C., Gonçalves T., Fernandes J.I., Camargo R.B.P. \& Nogueira V.A. 2019. Primary Solid Pulmonary Adenocarcinoma in a Dog. Acta Scientiae Veterinariae. 47(Suppl 1): 440. DOI: 0.22456/16799216.97395

21 Paoloni M. \& Khanna C. 2007. Comparative Oncology Today. Veterinary Clinics of North America: Small Animal Practice. 37(6): 1023-1032. DOI: 10.1016/j.cvsm.2007.08.003

22 Ramos-Vara J.A., Miller M.A. \& Johnson G.C. 2005. Usefulness of thyroid transcription factor-1 immunohistochemical staining in differential diagnosis of primary pulmonar tumors of dogs. Veterinary Pathology. 42(3): 315-320. DOI: $10.1354 / v p .42-3-315$

23 Rossetto V.J.V., Rahal S.C., Pardini L.M., Fabris V.E., Mamprim M.J. \& Ribeiro S.M. 2014. Undifferentiated pulmonary adenocarcinoma of clear cells associated to hypertrophic osteopathy in a dog. Acta Scientiae Veterinariae. 43(Suppl 1): 65. 6p.

24 Souza T.M., Fighera R.A. Irigoyen L.F. \& Barros C.S.L. 2006. Estudo retrospectivo de 761 tumores cutâneos em cães. Ciência Rural. 36(2): 555-560. DOI: 10.1590/S0103-84782006000200030

25 White R.N. \& Lascelles B.D.X. 2003. Tumours of the respiratory system and thoracic cavity. In: Dobson J.M. \& Lascelles B.D.X. (Eds). BSAVA Manual of Canine and Feline Oncology. 2nd edn. Gloucester: British Small Animal Veterinary Association, pp.259-275.

26 Wilson D.W. 2017. Tumors of the respiratory tract. In: Meuten D.J. (Ed). Tumors in Domestic Animals. 5th edn. Jersey City: John Wiley \& Sons, pp.467-498.

27 Withrow S.J. 2007. Lung cancer. In: Vail D.M. \& Withrow S.J. (Eds). Withrow and MacEwen's Small Animal Clinical Oncology. 4th edn. St. Louis: Saunders Elsevier, pp.517-525. 